\title{
Preface to the first German edition
}

This book is based on a lecture course which has been given by the author for more than 10 years at the Ludwig-Maximilian University Munich (LMU) in the postgraduate Master lecture series, to introduce the reader to the chemistry of highly energetic materials. This book also reflects the research interests of the author. It was decided to entitle the book "Chemistry of High-Energy Materials" and not simply "Chemistry of Explosives" because we also wanted to include pyrotechnics, propellant charges and rocket propellants into the discussion. On purpose we do not give a comprehensive historical overview and we also refrained from extensive mathematical deductions. Instead we want to focus on the basics of chemical explosives and we want to provide an overview of recent developments in the research of energetic materials.

This book is concerned with both the civil applications of high-energy materials (e.g. propellants for carrier or satellite launch rockets and satellite propulsion systems) as well as the many military aspects. In the latter area there have been many challenges for energetic materials scientists in recent days some of which are listed below:

- In contrast to classical targets, in the on-going global war on terror (GWT), new targets such as tunnels, caves and remote desert or mountain areas have become important.

- The efficient and immediate response to time critical targets (targets that move) has become increasingly important for an effective defense strategy.

- Particularly important is the increased precision ("we want to hit and not to miss the target”, Adam Cumming, DSTL, Sevenoaks, U.K.), in order to avoid collateral damage as much as possible. In this context, an effective coupling with the target is essential. This is particularly important since some evil regimes often purposely co-localize military targets with civilian centers (e.g. military bases near hospitals or settlements).

- The interest in insensitive munitions (IM) is still one of the biggest and most important challenges in the research of new highly energetic materials.

- The large area of increasing the survivability (for example by introducing smokeless propellants and propellant charges, reduced signatures of rocket motors and last but not least, by increasing the energy density) is another vast area of huge challenge for modern synthetic chemistry.

- Last but not least, ecological aspects have become more and more important. For example, on-going research is trying to find suitable lead-free primary explosives in order to replace lead azide and lead styphnate in primary compositions. Moreover, RDX shows significant eco- and human-toxicity and research is underway to find suitable alternatives for this widely used high explosive. Finally, in the area of rocket propulsion and pyrotechnical compositions, replacements for toxic ammonium perchlorate (replaces iodide in the thyroid 
gland) which is currently used as an oxidizer are urgently needed. Despite all this, the performance and sensitivity of a high-energy material are almost always the key-factors that determine the application of such materials - and exactly this makes research in this area a great challenge for synthetically oriented chemists.

The most important aspect of this book and the corresponding lecture series at LMU Munich, is to prevent and stop the already on-going loss of experience, knowledge and know-how in the area of the synthesis and safe handling of highly energetic compounds. There is an on-going demand in society for safe and reliable propellants, propellant charges, pyrotechnics and explosives in both the military and civilian sector. And there is no one better suited to provide this expertise than well trained and educated preparative chemists.

Last but not least, the author wants to thank those who have helped to make this book project a success. For many inspired discussions and suggestions the authors wants to thank the following colleagues and friends: Dr. Betsy M. Rice, Dr. Brad Forch and Dr. Ed Byrd (US Army Research Laboratory, Aberdeen, MD), Prof. Dr. Manfred Held (EADS, TDW, Schrobenhausen), Dr. Ernst-Christian Koch (NATO MSIAC, Brussels), Dr. Miloslav Krupka (OZM, Czech Republic), Dr. Muhamed Sucesca (Brodarski Institute, Zagreb, Croatia), Prof. Dr. Konstantin Karaghiosoff (LMU Munich), Prof. Dr. Jürgen Evers (LMU Munich), as well as many of the past and present co-workers of the authors research group in Munich without their help this project could not have been completed.

The author is also indebted to and thanks Dipl.-Chem. Norbert Mayr (LMU Munich) for his support with many hard- and soft-ware problems, Ms. Carmen Nowak and Ms. Irene S. Scheckenbach (LMU Munich) for generating many figures and for reading a difficult manuscript. The author particularly wants to thank Dr. Stephanie Dawson (de Gruyter) for the excellent and efficient collaboration. 
